\title{
PENERAPAN STRATEGI MARKETING BERBASIS INOVASI BAGI PENGRAJIN GERABAH DESA GEBANGSARI KLIRONG KEBUMEN
}

\section{THE IMPLEMENTATION OF INNOVATION BASED MARKETING STRATEGY FOR POTTERY CRAFTSMEN OF GEBANGSARI, KLIRONG KEBUMEN}

\author{
Dani Rizana $^{1 *}$, Akhmad Syarifudin ${ }^{2)}$ \\ ${ }^{1)}$ Prodi Manajemen, STIE Putra Bangsa, email: danirizana@gmail.com \\ ${ }^{2)}$ Prodi Akuntansi, STIE Putra Bangsa, email: akhmadsyarifudin89@gmail.com
}

\begin{abstract}
ABSTRAK
Gerabah Gebangsari merupakan salah satu satu produk khas desa Gebangsari yang diwariskan secara turun temurun namun belum mampu meningkatkan perekonomian pengrajin sehingga banyak yang beralih ke usaha lain seperti buruh genteng dan batu bata, Minimnya pengetahuan srategi marketing dan kurangnya nilai ekonomis gerabah menyurutkan pengrajin untuk menekuni kerajinan gerabah ini, ditambah lagi adanya pandemi covid 19 yang saat ini melanda seluruh dunia. Mitra pengabdian masyarakat ini adalah pengrajin gerabah desa Gebangsari kecamatan Klirong Kabupaten Kebumen. Metode yang digunakan dalam pengabdian ini yaitu FGD, penyuluhan dan pendampingan. Target permasalahan prioritas yang segera ditangani dalam kegiatan pengabdian ini adalah masalah strategi marketing. Tujuan kegiatan pengabdian masyarakat ini sebagai upaya pemecahan atas permasalahan yang ada sehingga dapat membentuk masyarakat yang mandiri secara ekonomi melalui pengetahuan dan ketrampilan khususnya bidang marketing sehingga memperluas pasar dan volume penjualan serta efisiensi biaya produksi dan pemasaran. Output yang diberikan ke pengrajin berupa alat peraga marketing, banner dan alat putar gerabah elektronik. Hasil menunjukkan bahwa kegiatan yang dilaksanakan (1) dapat menggali permasalahan permasalahan yang dihadapi pengrajin khususnya dibidang marketing yang akhirnya dapat menumbuhkan motivasi tinggi untuk pengembangan usaha produksi gerabah (2) menambah pengetahuan strategi marketing sehingga meningkatkan volume penjualan pasca pandemi covid 19.
\end{abstract}

Kata kunci: Pengrajin, Gerabah, Strategi, Marketing

\section{ABSTRACT}

Gebangsari pottery is one of the typical products of Gebangsari village that has been passed down from generation to generation but has not been able to improve the craftsmen's economy. This condition makes many of craftsmen have switched to other businesses such as tile and brick. The lack of marketing strategies knowledge and the pottery economic value have discouraged craftsmen from pursuing this pottery craft. It is worsen by the current condition affected by the Covid-19 pandemic sweeping the entire world. Community service partners of this program were pottery craftsmen in Gebangsari, Klirong, Kebumen. The method used in this service was FGD namely counseling and mentoring. The immediately handled issue of this service activity are those related to marketing strategy. Purpose of this community service activity is as an effort to solve existing problems so that they can form an economically independent society through knowledge and skills. The existing problem to tackle is especially in the field of marketing so as to expand the market and sales volume as well as the efficiency of production and marketing costs. The outputs given to the craftsmen were in the form of marketing props, banners, and electronic earthenware rotary tools. The results show that the activities carried out (1) can explore the problems faced by craftsmen, especially in the marketing sector, which in turn can foster high motivation of pottery production business development and 2) increase marketing strategies knowledge in order to intensify sales volume after the Covid-19 pandemic.

Keywords: Craftsmen, Pottery, Strategy, Marketing 


\section{PENDAHULUAN}

Desa Gebangsari terletak di bagian selatan Kecamatan Klirong Kabupaten Kebumen, memiliki jarak $6 \mathrm{~km}$ dari garis pantai selatan dan berbatasan dengan Kecamatan Petanahan di sebelah baratnya, yaitu desa Jogomertan, sedangkan sebelah timur adalah Desa Klegenrejo, sebelah utara Desa Klirong dan disebelah selatan Desa Tambakprogaten. Desa Gebangsari memiliki luas wilayah 136 ha yang terdiri dari wilayah pertanian dan pemukiman. Sedangkan jumlah penduduk Desa Gebangsari sebanyak 2434 jiwa terdiri dari 1191 laki-laki dan 1243 perempuan.

Kondisi ekonomi Desa Gebangsari saat ini masih dikategorikan sebagai desa dengan tingkat ekonomi rendah. Hal tersebut disebabkan oleh berbagai permasalahan yang cukup komplek, kurangnya peluang dan lapangan pekerjaan, potensi wirausaha yang susah ditempuh dan perihal lainnya, sehingga mempengaruhi tingkat pendapatan masyarakat sangat kurang, hal tersebut memaksa masyarakat di usia produktif yang total berjumlah sekitar 1300 jiwa sebagian meninggalkan desa untuk mengadu nasib diluar daerah.

Melihat kondisi yang ada maka Pemerintah Desa berupaya mengangkat peluang yang tampak nyata untuk menggerakan sektor ekonomi masyarakat dalam perspektif Pemerintahan Desa yaitu melalui pengembangan BUMDes dan unitunit usahanya. Untuk itu perlu kiranya bagi pengrajin Gerabah di Desa Gebangsari dilakukan capacity building, proses atau kegiatan memperbaiki kemampuan seseorang, kelompok, organisasi atau sistem untuk mencapai tujuan atau kinerja yang lebih baik. Capacity building adalah pembangunan keterampilan (skills) dan kemampuan (capabilities), seperti kepemimpinan, manajemen, keuangan dan pencarian dana, program dan evaluasi, supaya pembangunan organisasi efektif dan berkelanjutan. Ini adalah proses membantu individu atau kelompok untuk mengidentifikasi dan menemukan permasalahan dan menambah wawasan, pengetahuan dan pengalaman yang dibutuhkan untuk memecahkan masalah dan melakukan perubahan [1].

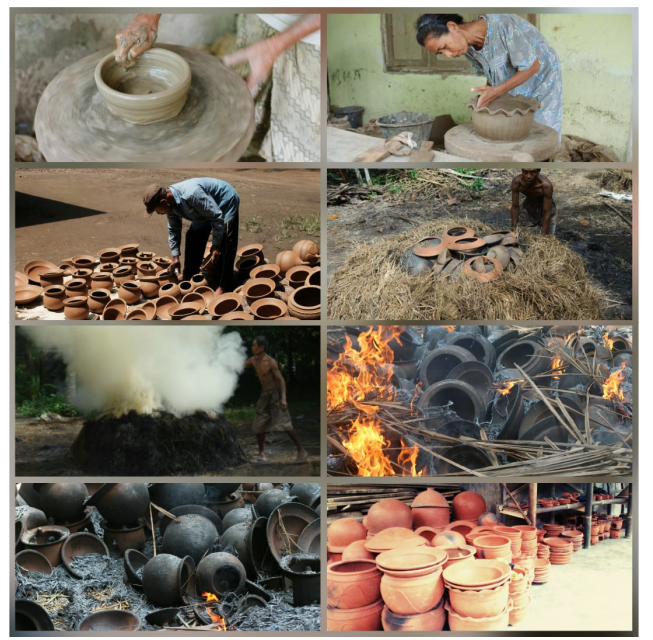

Gambar 1. Proses Produksi Gerabah

Capacity building difasilitasi melalui penetapan kegiatan bantuan teknik, meliputi pendidikan dan pelatihan, bantuan teknik khusus (specific technical assitance) dan penguatan jaringan.

Gerabah telah lama dikenal baik sebagai peralatan rumah tangga ataupun souvenir [2]. 
Gerabah Gebangsari merupakan salah satu satu produk khas desa Gebangsari yang diwariskan secara turun temurun namun belum mampu meningkatkan perekonomian warga masyarakat dikarenakan minimnya jumlah permintaan gerabah sehingga banyak yang beralih buruh batu bata atau genteng bahkan banyak pengrajin usia produktif yang berpindah ke kota besar untuk mencari pekerjaan, pengrajin belum mempunyai sebuah galeri atau media pemasaran gerabah sehingga sulit untuk memasarkan produk gerbah itu sendiri, produk yang dihasilkan masih kalah bersaing dengan daerah lain dikarenakan finishing yang kurang baik, kurangnya nilai ekonomis gerabah menyurutkan generasi muda untuk menekuni potensi kerajinan gerabah ini. Menurut [5] mengatakan sebagian besar permasalahan bersumber dari kelemahan internal kelompok pengrajin gerabah yaitu kemampuan sumber daya manusia, produksi dan kemampuan memasarkan produk. Terlebih Saat ini yang merupakan era digital sehingga pelaksanaan pemasaran online sangat diperlukan [6].

Penjualan kerajinan gerabah sebenarnya merupakan kegiatan ekonomi yang menjanjikan jika dikelola dengan baik, mulai dari proses pencarian bahan hingga pemasaran ke masyarakat luas [4].

Berdasarkan latar belakang diatas diperlukan kegiatan pengabdian masyarakat sebagai upaya pemecahan atas permasalahan yang ada sehingga dapat membentuk masyarakat yang mandiri secara ekonomi melalui pengetahuan dan keterampilan produksi gerabah, meningkatkan kualitas produk dan varian gerabah yang diproduksi, meningkatkan volume produksi, memperluas pasar dan volume penjualan serta efisiensi biaya produksi dan pemasaran [3].

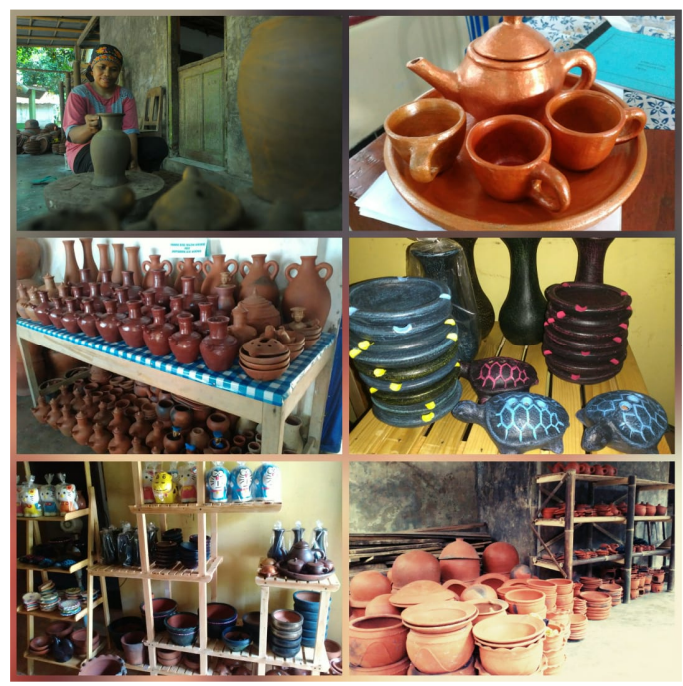

Gambar 2. Keadaan produk dan pemasaran masih manual

Sedang manfaat yang diharapkan dari pengabdian masyarakat ini adalah: 1) tumbuhnya motivasi tinggi untuk pengembangan usaha produksi gerabah pasca pandemi, 2) meningkatnya kuantitas dan kualitas produk gerabah pasca pandemi covid 19 3) meningkatnya produksi gerabah sehingga dapat meningkatkan pendapatan dan kesejahteraan pengrajin, 4) meningkatkan pengetahuan startegi marketing/pemasaran untuk mengembangkan jangkauan pemasaran

\section{METODE PELAKSANAAN KEGIATAN}

Metode kegiatan yang dilakukan adalah pelatihan teori dan disertai aplikasi yang diberikan. Kegiatan ini dilakukan untuk mematangkan pengetahuan pengrajin 
gerabah,khususnya marketing sehingga setelah program ini selesai, para pengrajin gerabah masih bisa mengaplikasikan semua materi pelatihan yang diberikan. Adapun prosedur pelaksanaan kegiatan ini adalah sebagai berikut:

Tabel 1. Metode pelaksanaan

\begin{tabular}{|c|c|c|}
\hline No & Jenis metode & Prosedur \\
\hline 1. & $\begin{array}{l}\text { Focus Group } \\
\text { Discussion } \\
\text { (FGD) }\end{array}$ & $\begin{array}{l}\text { a. Kordinasi } \\
\text { pelaksanaan } \\
\text { FGD } \\
\text { b. Penjadwalan } \\
\text { FGD } \\
\text { c. Pelaksanaan pre- } \\
\text { test } \\
\text { d. Pelaksanaan } \\
\text { FGD }\end{array}$ \\
\hline 2. & $\begin{array}{l}\text { Pelatihan/ } \\
\text { Penyuluhan }\end{array}$ & $\begin{array}{l}\text { a. } \text { Kordinasi } \\
\text { pelatihan } \\
\text { b. Penjadwalan } \\
\text { pelatihan } \\
\text { c. Persiapan bahan } \\
\text { dan alat } \\
\text { d. Pelaksanaan } \\
\text { pelatihan } \\
\text { Marketing } \\
\text { e. Pelaksanaan post } \\
\text { test }\end{array}$ \\
\hline 3. & Pendampingan & $\begin{array}{l}\text { a. Pelaksanaan } \\
\text { pendampingan } \\
\text { b. Evaluasi } \\
\text { keberhasilan }\end{array}$ \\
\hline
\end{tabular}

\section{Focus Group Discussion (FGD)}

Tahap persiapan yang dilakukan adalah berkordinasi dengan kepala desa dan perangkat Desa terkait persiapan kegiatan FGD (Focus Group Discussion) dan Kegiatan Pelatihan serta mendata pengrajin gerabah yang ada di Desa Gebangsari. Setelah data diperoleh secara komplit, kemudian pengrajin tersebut dibagi menjadi kelompok dengan masing-masing kelompok terdiri dari 5 orang anggota. Setelah kelompok terbentuk, kemudian dilakukan penyiapan material yang akan digunakan untuk proses kegiatan penyuluhan. Kegiatan FGD ini bertujuan menggali permasalahan yang ada pada pengraji terkait srtategi marketing.

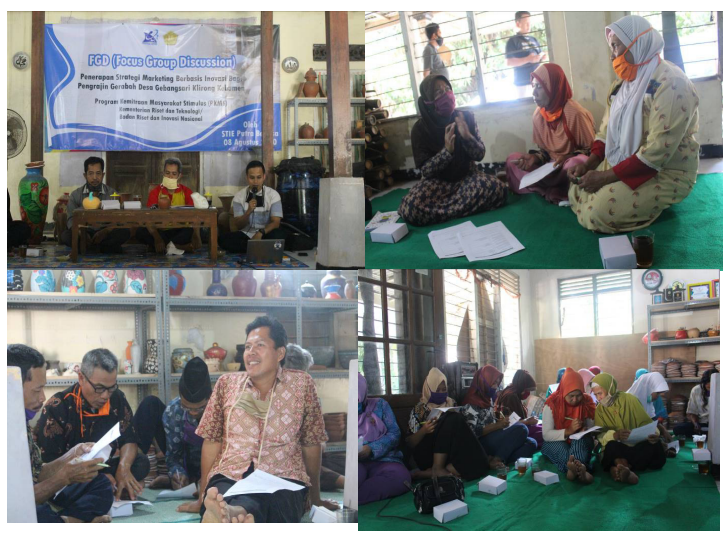

Gambar 3. Kegiatan FGD (Focus Group Discussion)

\section{Pelatihan}

Pada pelaksanaan pelatihan pengabdian masyarakat digebangsari mengundang dua narasumber yang dihadirkan yakni Praktisi Bisnis Nasional Joko Fitra, M.Sc., M.M. dan pakar marketing sekaligus dosen STIE Putra Bangsa Dr. Sigit Wibawanto SE., M.M. Joko Fitra memaparkan bahwa pada umumnya marketing dimaknai sempit yakni transaksi. Padahal kunci marketing yang tepat yakni gaungkan iklan dulu sebelum mencari transaksi. Hingga kini pada umumnya marketing masih dilaksanakan dengan sangat sederhana yakni memasang foto produk di Facebook yang disertai dengan harga. Padahal seharusnya tidak seperti itu. keinginan yang kuat untuk cepat mencapai transaksi justru akan menjadi penghambat bagi tercapainya transaksi. Untuk itu hal terpenting yakni mengiklankan 
produk. Artinya memberi informasi kepada masyarakat terkait produk tersebut. Informasi atau iklan tersebut harus masif dilaksanakan. Joko selaku narasumber 1 juga mengingatkan pentingnya penggunaan media sosial secara terintegrasi dan terpadu. Dalam hal ini Facebook atau Instagram merupakan media yang sangat tepat untuk mengenalkan atau menginformasikan produk. Sedangkan website berfungsi untuk menjelaskan rinci dengan deskripsi produk tersebut. Sama dengan Website, Youtube menjelaskan secara visual, sedangkan Whatsapp untuk melakukan transaksi. Sedangkan Sigit Wibawanto menjelaskan tentang pentingnya inovasi produk. Dia mendorong perajin gerabah di Desa Gebangsari terus melakukan inovasi.

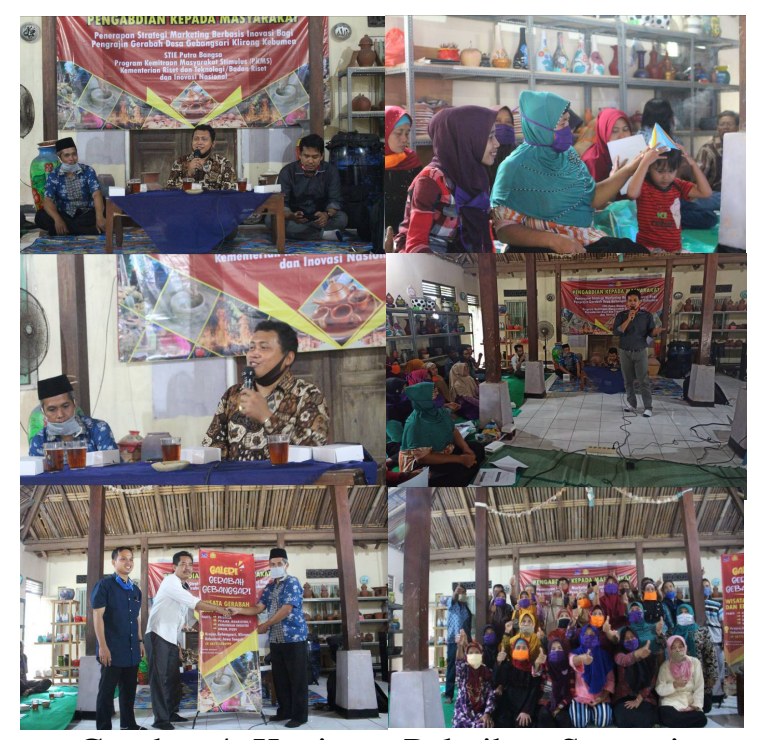

Gambar 4. Kegiatan Pelatihan Strategi Marketing dan pemberian alat peraga marketing

\section{HASIL DAN PEMBAHASAN}

Hasil yang dicapai (Output) yang didapat dari kegiatan pengabdian masyarakat ini diantaranya adalah 1) Tumbuhnya motivasi tinggi untuk pengembangan usaha produksi gerabah pasca covid 19, 2) Meningkatnya kuantitas dan kualitas produk gerabah pasca covid 19, 3) Meningkatnya produksi Gerabah sehingga dapat meningkatkan pendapatan dan kesejahteraan pengrajin,

Meningkatkan pengetahuan startegi marketing/pemasaran untuk mengembangkan jangkauan pemasaran. Ketercapaian sasaran yang dari kegiatan pengabdian masyarakat ini diantaranya adalah 1) Bangkitnya motivasi tinggi untuk pengembangan usaha produksi gerabah pasca pandemi, 2) Pengrajin mempunyai semangat kembali pasca pandemi dalam merawat galeri gerabah sebagai sarana promosi secara gotong royong, 3) Tumbuhnya kesadaran masyarakat terkait pengetahuan strategi marketing sehingga meningkatkan volume penjualan pasca pandemi covid 19.

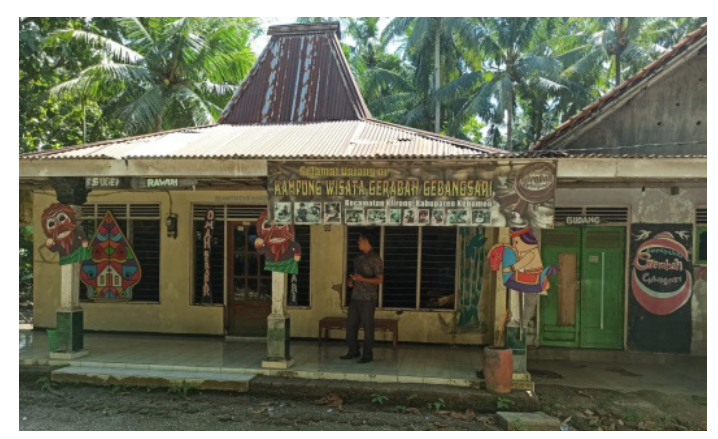

Gambar 5. Kondisi Galeri Gerabah sebelum pengabdian

Pada Gambar 5 diatas merupakan gambar keadaan galeri gerabah yang cukup memprihatinkan, dimasa pandemi galeri gerabah tutup total dan tidak pernah dibersihkan. 


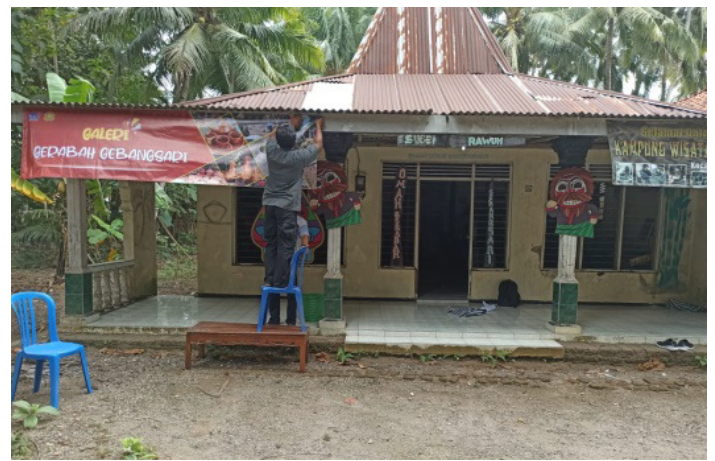

Gambar 6 Penataan Kembali Galeri Gerabah

Pada Gambar 6 kelompok pengrajin bergotong royong untuk membersihkan galeri untuk memulai kembali dan aktivitas pasca pandemi agar geliat edukasi wisata gerabah kembali normal sehingga produktivitas pengrajin meningkat kembali.
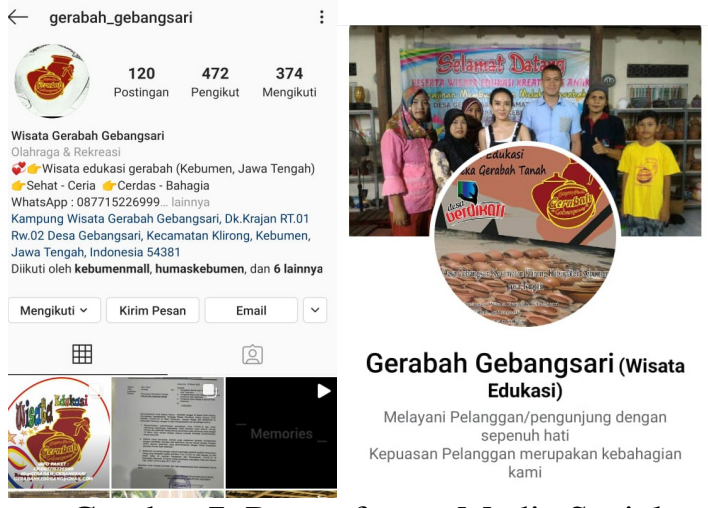

Gerabah Gebangsari (Wisata Edukasi)

Melayani Pelanggan/pengunjung dengan Kepuasan Pelanggan merti

Gambar 7. Pemanfaatan Media Sosial Instagram dan FB

Selain Galeri gerabah dalam rangka mendukung kegiatan marketing, juga menggunakan media social dan website. Media sosial merupakan suatu bentuk promosi melalui media digital. Media sosial digunakan untuk membangun ketertarikan setiap individu untuk membangun hubungan sosial melalui dunia maya. Dengan adanya media sosial sebagai media marketing gerabah memungkinkan terjadinya arus informasi timbal balik yang membuat pengguna media sosial dapat menemukan informasi dengan cepat dan mudah.

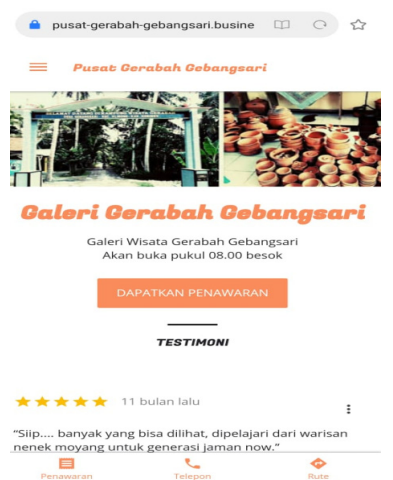

Gambar 7. Pemanfaatan website untuk marketing

\section{KESIMPULAN}

Kesimpulan kegiatan pengabdian masyarakat yang telah dilaksanakan Di Desa Gebangsari Kecamatan Klirong Kabupaten Kebumen pada kelompok pengrajin gerabah ini adalah:

1. Kegiatan FGD (Focus Gruop Discussion) membahas terkait kendala kendala yang tengah dihadapi oleh para pengrajin gerabah, khususnya ditengah pandemi covid 19, sehingga dalam kegiatan ini dapat menggali permasalahan permasalahan yang dihadapi pengrajin khususnya dibidang marketing. Yang akhirnya dapat menumbuhkan motivasi tinggi untuk pengembangan usaha produksi gerabah pasca covid 19.

2. Kegiatan Pelatihan Strategi Marketing Berbasis Inovasi Bagi Pengrajin Gerabah Desa Gebangsari Klirong Kebumen sesuai dengan kendala kendala dan permasalahan yang didiskusikan pada kegiatan FGD sebelumnya, hasil dari pelatihan ini sebagai kegiatan stimulus untuk membangkitkan kesadaran masyarakat 
terkait pengetahuan strategi marketing

sehingga meningkatkan volume penjualan

pasca pandemi covid 19.

\section{SARAN}

Berdasarkan simpulan, maka pengabdi memberikan beberapa saran sebagai berikut:

1. Pemerintah Desa hendaknya dapat mengajukan atau menganggarkan anggaran untuk meingkatkan akses jalan menuju Desa Gebangsari sehingga para pengunjung/ wisatawan akan lebih mudah dalam mencari produk gerabah

2. Pengelolaan manajemen dalam wisata edukasi antara pemdes, Bumdes ataupu Pokdarwis agar lebih dimaksimalkan sehingga nantinya tidak menimbulkan polemik dikemudian hari.

3. Pemdes dan Pokdarwis lebih giat lagi dalam memasarkan produk ataupun edukasi wisata guna mendatangkan wisata sebanyak banyaknya

\section{UCAPAN TERIMAKASIH}

Terimakasih kami sampaikan kepada Kementerian Riset dan Teknologi/ Badan Riset dan Inovasi Nasional Republik Indonesia dan STIE Putra Bangsa Kebumen, P4M STIE Putra Bangsa yang telah memfasilitasi kegiatan pengabdian masyarakat, ucapan terimakasih juga kami sampaikan kepada Kepala Desa Gebangsari Kecamatan Klirong, kelompok Pokdarwis dan segenap pengrajin Gerabah sebagai mitra pengabdian

\section{REFERENSI}

[1] Campobasso, L and D Davis, (2001). Reflection on Capacity Building, the California Wellness Foundation Journal, Volume 2 no. 2. California : Wellness Foundation

[2] Desita, D. N., Deni, M. R., Kholis, N., Khasanah, S., \& Malang, U. N. (2020). Marketing Online untuk Memperluas Pangsa Pasar Inovasi Kerajinan Gerabah Desa Tondowulan Jombang. 3(2). Retrieved from http://journal2.um.ac.id/index.php/jki/ar ticle/view/12742

[3] Direktorat Riset dan Pengabdian Masyarakat. (2019). Panduan Penelitian dan Pengabdian Kepada Masyarakat Edisi XII. Retrieved from simlitabmas.ristekdikti.go.id/

[4] Gita Purwasih, J. H., Wijaya, M., \& Kartono, D. T. (2019). Strategi Bertahan Hidup Perajin Gerabah Tradisional. Jurnal Antropologi: Isu-Isu Sosial Budaya, 2l(2), 159. https://doi.org/10.25077/jantro.v21.n2.p 159-167.2019

[5] Meilan Sugiarto, Ida Susi Dewanti, Adi Suprapto, dan S. (2017). IbM Bagi Kelompok Pengrajin Gerabah Dusun Pagerjurang Klaten Sebagai Upaya Meningkatkan Kapabilitas Usaha. Journal of Chemical Information and Modeling, 53(9), 1689-1699. Retrieved from

https://journal.uny.ac.id/index.php/inote k/article/view/11287

[6] Schwarzl, S., \& Grabowska, M. (2015). Online marketing strategies: The future is here. Journal of International Studies, $8(2)$, 187-196. https://doi.org/10.14254/20718330.2015/8-2/16 